\title{
TRANSPARÊNCIA PÚBLICA PASSIVA: UMA ANÁLISE DE SEUS DETERMINANTES NO ESTADO DE MINAS GERAIS
}

\section{PASSIVE PUBLIC TRANSPARENCY: AN ANALYSIS OF ITS DETERMINANTS IN THE STATE OF MINAS GERAIS}

Artigo foi aprovado e apresentado no V Simpósio Integrado de Administração Pública (SINTAP), realizado de 03 a 05/10 de 2019, em Teófilo Otoni (MG).

\begin{abstract}
RESUMO
Este estudo objetiva analisar os fatores determinantes da transparência pública passiva nos municípios abrangidos pelo Índice Escala Brasil Transparente no estado de Minas Gerais, no ano de 2016. O Índice Escala Brasil Transparente caracteriza-se pela situação de passividade do ente público, ou seja, de esperar por um pedido de informação a ser realizado pelo interessado. Deste modo, a partir de uma amostra formada por 204 municípios, estima-se um modelo Tobit, utilizando, como variável a ser explicada, o Índice Escala Brasil Transparente e, como variáveis explicativas, o Produto Interno Bruto (PIB) per capita, Índice Firjan de Desenvolvimento Municipal, escolaridade da população, idade do gestor municipal, receita orçamentária per capita e dummies para as regiões mineiras: Centro, Jequitinhonha/Mucuri, Noroeste, Norte, Rio Doce, Sul e Triângulo. Os resultados revelam relação estatística significativa entre a transparência pública passiva e as variáveis PIB per capita, idade do gestor municipal, Índice Firjan de Desenvolvimento Municipal, receita orçamentária per capita e escolaridade da população. Quanto às dummies regionais, identifica-se que, em geral, as diferenças existentes entre as regiões do estado mineiro condicionam o resultado da transparência passiva dos entes públicos municipais.
\end{abstract}

Palavras-Chave: Gestão Pública Municipal, Transparência Passiva, Escala Brasil Transparente.

\section{ABSTRACT}

This study aims to analyze the determinants of passive public transparency in the municipalities covered by the Transparent Brazil Scale Index in the state of Minas Gerais, in 2016. The Transparent Brazil Scale Index is characterized by the situation of the passivity of the public entity, that is, waiting for a request for information to be made by the interested party. Thus, from a sample of 204 municipalities, a Tobit model is estimated, using the Transparent Brazil Scale Index, as the variable to be explained, and, as explanatory variables, the per capita Gross Domestic Product (GDP), Firjan Municipal Development Index, schooling of the population, age of the municipal manager, budget revenue per capita and dummies for the state regions: Centro, Jequitinhonha/Mucuri, Noroeste, Norte, Rio Doce, Sul and Triângulo. The results reveal a statistically significant relationship between passive public transparency and the variables GDP per capita, age of the municipal manager, Firjan Municipal Development Index, budget revenue per capita and schooling of the population. Regarding to the regional dummies, it is identified that, in general, the existing differences between the regions of the state of Minas Gerais lead to the result of the passive transparency of municipal public entities.

Keywords: Municipal Public Management, Passive Transparency, Transparent Brazil Scale.
Hortência Geórgia dos Santos Graduada em Administração pela Universidade Federal dos Vales do Jequitinhonha e Mucuri (UFVJM). Tecnóloga em Gestão Pública pela Universidade Norte do Paraná (UNOPAR). Graduada em Ciências Contábeis pela Universidade Federal dos Vales do Jequitinhonha e Mucuri (UFVJM). E-mail: hortenciatem@ gmail.com

Elizete Aparecida de Magalhães Doutora em Economia Aplicada pela Universidade Federal de Viçosa (UFV). Mestre em Administração pela Universidade Federal de Viçosa (UFV). Graduada em Ciências Contábeis pela Universidade Federal de Viçosa (UFV). Docente do Curso de Ciências Contábeis da Universidade Federal dos Vales do Jequitinhonha e Mucuri (UFVJM). E-mail: elizete.am@ufvjm. edu.br
Kenia Fabiana Cota Mendonça
Mestre em Administração pela Universidade Federal de Lavras (UFLA). Graduada em Ciências Contábeis pela Universidade Federal de Minas Gerais (UFMG). Docente do curso de Ciências Contábeis na Universidade Federal dos Vales do Jequitinhonha e Mucuri (UFVJM). E-mail: kenia.mendonca@ufvjm. edu.br
Lis Daiana Bessa Taveira Mestre em Ciências contábeis pelo Programa Multi Institucional UNB/UFPB/UFRN Especialista em gestão fiscal e tributária pelo UNI/RN. Graduada em Ciências Contábeis pela UNIFACEX/RN. Docente do curso de Ciências contábeis da Universidade Federal dos Vales do Jequitinhonha e Mucuri (UFVJM). E-mail: lisbessa@ufvjm.edu.br 


\section{INTRODUÇÃO}

A transparência das ações dos gestores e seus impactos no setor público têm se tornado cada vez mais presente na formulação das diretrizes de planejamento estratégico para a gestão eficiente da máquina pública. Assim, devido a sua complexidade e importância, o tema Transparência Pública vem sendo objeto de vários estudos. Essas investigações, em sua maioria, buscam identificar falhas no processo de gestão e mostrar o que de fato ocorre com o orçamento público, a fim de trazer mais informações para a sociedade.

Segundo a Controladoria Geral da União [CGU] (2018a), uma gestão pública transparente permite que uma sociedade mais informada venha a colaborar no controle das ações de seus representantes, com o objetivo de confirmar se realmente os recursos públicos estão sendo gastos de forma correta.

As ações da administração pública interferem diretamente no processo de desenvolvimento da federação. Essas atuações visam à garantia de um processo justo e democrático da transparência, e, tendo em vista a aplicação correta dos recursos públicos, a publicidade e transparência desses atos passaram a ser exigidos por força de lei.

Neste sentido, a partir da Lei de Responsabilidade Fiscal (LRF), Lei Complementar $n^{\circ} 101 / 2000$, ficaram estabelecidas as normas de finanças públicas voltadas para a responsabilidade na gestão fiscal, que visam à ação planejada dos recursos públicos, instituindo a obrigatoriedade da transparência como forma de evitar riscos e corrigir desvios capazes de afetar o equilíbrio das contas públicas.

No ano de 2009, foi promulgada a Lei Complementar nº 131 (Lei da Transparência), que acrescentou dispositivos à LC n ${ }^{\circ} 101 / 2000$, com a finalidade de determinar a disponibilização, em tempo real, de informações pormenorizadas sobre a execução orçamentária e financeira da União, dos Estados, do Distrito Federal e dos Municípios (Lei n 131/2009).

Neste contexto, surgiu, para regulamentar o direito de acesso à informação, a Lei n 12.527 , de 18 de novembro de 2011, conhecida como Lei de Acesso à Informação (LAI). A LAI criou mecanismos que possibilitam qualquer pessoa, sem necessidade de apresentar motivo ou justificativa, receba informações públicas requeridas a órgãos e entidades (Lei n 12.527/2011).

A legislação brasileira normatiza a transparência passiva e ativa. Segundo Possamai \& Souza (2020), Araujo \& Tejedo-Romero (2016) e CGU (2013), a transparência passiva ocorre quando um pedido de informação a algum órgão ou ente é solicitado pela sociedade a fim de prestar informações, quer sejam de interesse particular ou coletivo, desde que estas não sejam resguardadas por sigilo. Já na transparência ativa, a iniciativa em divulgar as informações parte do gestor público, que pode publicar na internet apenas o conteúdo mínimo previsto em lei.

Devido a esta obrigatoriedade de promover e fiscalizar o aumento no nível de transparência dos atos públicos, o Ministério da Transparência, juntamente com a CGU, criou o Índice Escala Brasil Transparente (EBT), como ferramenta para efetivar o trabalho dos órgãos fiscalizadores e, com metodologia própria, gerar informações quanto à transparência em estados e municípios brasileiros (CGU, 2015). Neste estudo, o nível de transparência pública é medido pela EBT, que tem a finalidade de avaliar o grau de cumprimento às normas da Lei de Acesso à Informação.

A Transparência Pública tem se tornado, cada vez mais, fonte de investigação acadêmica, destacando-se os trabalhos de Possamai \& Souza (2020), Lacerda, Helal \& Cabral (2017), W. A. de O. Silva (2017), Melo, Martins \& Martins (2016), Leite, Colares \& Andrade (2015) e Zuccolotto \& Teixeira (2014). Muitos desses autores, em suas pesquisas, buscaram explicar as variáveis sociais e econômicas que poderiam afetar a transparência pública.

No presente trabalho, busca-se identificar os determinantes da transparência pública passiva nos municípios abrangidos pelo Índice EBT do estado de Minas Gerais, no ano de 2016. Diante dos estudos analisados e tendo como pilar principal de investigação a transparência passiva, esta pesquisa visa avançar na discussão acerca dos fatores econômicos, sociais e financeiros que possam afetar o nível de transparência passiva em nível municipal. Além disso, procura-se analisar como as características regionais de natureza cultural, social, demográfica, institucional e política determinam o nível de transparência dos municípios analisados, tendo em vista que a legislação pertinente à temática é única e homogênea, independente do porte populacional, do nível de desenvolvimento e da capacidade de gestão do município.

Dado o exposto, e a partir da constatação dos determinantes, os resultados podem ser úteis para repensar, ou até mesmo reformular, normas referentes à transparência pública, bem como auxiliar no debate sobre a necessidade do desenvolvimento de políticas voltadas para o aperfeiçoamento da transparência passiva, e, assim, tentar minimizar as diferenças regionais, buscando padronização das divulgações das informações (devido à não obrigatoriedade da transparência passiva), trazendo maior visibilidade da gestão municipal e aproximando ainda mais a sociedade dos entes públicos.

Este estudo é composto por cinco seções, incluindo esta parte introdutória. A seção 2 trata da transparência pública. A seção 3 delineia a metodologia empregada. As seções 4 e 5 apresentam as discussões dos resultados e as conclusões do estudo.

\section{REFERENCIAL TEÓRICO}

\subsection{Transparência Pública}

O tema transparência pública, inicialmente, surgiu no Brasil como forma de complementação ao princípio constitucional da publicidade. A Constituição Federal de 1988 (CF/88) prevê em seu artigo $5^{\circ}$ que: 
XXXIII - todos têm direito a receber dos órgãos públicos informações de seu interesse particular, ou de interesse coletivo ou geral, que serão prestadas no prazo da lei, sob pena de responsabilidade, ressalvadas aquelas cujo sigilo seja imprescindível à segurança da sociedade e do Estado.

No artigo 216, parágrafo $2^{\circ}$, a CF/88 estabelece que "cabem à administração pública, na forma da lei, a gestão da documentação governamental e as providências para franquear sua consulta a quantos dela necessitem." (Constituição da República Federativa do Brasil, 1988, n. p.).

A transparência dos atos públicos é fator determinante para o controle social e democrático. Deste modo, a disponibilização de informações confiáveis se configura essencial para que exista a participação cidadã, sendo um elemento necessário para o exercício da democracia (Vieira, 2012).

Após os preceitos de publicidade previstos pela CF/88, a temática da transparência da informação pública ganhou maior relevância no Brasil, a partir da LC n 101/2000, popularmente conhecida como Lei de Responsabilidade Fiscal. Desde então, outras leis, como a LC nº 131/2009 - Lei da Transparência - foram sendo elaboradas no intuito de garantir e otimizar o acesso às informações.

A referida lei obriga a disponibilização, em tempo real, de informações públicas como: receita, despesa, salário dos servidores públicos, convênios e outros, nos portais eletrônicos, nas várias esferas governamentais (Bairral, Silva \& Alves, 2015). Ainda de acordo com essa lei, os principais dados a serem oportunizados são relacionados à execução da despesa no momento de sua realização, com autorização mínima dos dados referentes ao processo de aquisição, fornecedor, bem ou serviço e outros, para deixar claro e identificado todo o processo.

Deste modo, os entes que compõem a estrutura da administração pública brasileira são constitucionalmente obrigados a prestar contas do uso de recursos públicos e a respeitar o princípio da publicidade. Segundo Tristão (2002), a transparência é considerada como a democratização do acesso às informações. Para Loureiro, Teixeira \& Pardo (2008), a transparência associa-se à divulgação de informações, por parte dos governos, para atores internos e externos, para sua consequente utilização como instrumento de responsabilização (accountability) dos agentes públicos, quando estes adotam algum procedimento inadequado ao bom uso dos recursos públicos.

De acordo com L. M. da Silva (2009), a transparência vai além dos atos de publicidade, ultrapassando também os limites da linha legal e fiscal, que envolvem o desempenho, os controles internos, documentos públicos e as ações dos agentes públicos. Assim, a transparência, exercida em sua totalidade, torna-se o principal agente transformador de uma administração pública eficiente.

Na visão de Zuccolotto, Teixeira \& Riccio (2015), a transparência pode ser entendida como a gestão dos assuntos públicos para a sociedade, em que todos têm acesso às decisões, ou sobre o que elas representam, como são tomadas e, consequentemente, seus benefícios e malefícios.

L. M. da Silva (2009), em outro ensinamento, afirma que a transparência não deve se reportar somente a fatos praticados pela atual administração pública, mas também devem ser garantidas as informações de períodos anteriores, de outras gestões, o que possibilita estudos de caráter evolutivo e comparativo acerca da atuação dos gestores.

A transparência pública pode ser observada em duas formas legais: transparência ativa e transparência passiva. A primeira forma pode ser entendida como a "divulgação de informações de interesse público, independentemente de solicitações", enquanto a segunda está ligada ao fato de que "qualquer interessado poderá apresentar pedido de acesso a informações aos órgãos e entidades” (Lei n 12.527/2011, n. p.).

Segundo Raupp (2016), a transparência ativa ocorre quando o ente público disponibiliza informações espontaneamente, sejam elas previstas ou não na lei, e, na ótica da transparência passiva, o fornecimento de dados parte por iniciativa do interessado, por meio de requerimentos e observações às situações de caráter sigiloso.

No entendimento de Silveira (2012), as informações públicas pertencem ao cidadão e não ao Estado, e quando essas não são disponibilizadas de forma ativa pelos gestores públicos, os interessados poderão solicitá-las, ocorrendo, portanto, a transparência passiva.

Em se tratando de transparência pública, um ponto relevante diz respeito à utilidade da informação disponibilizada ao cidadão. Dados os avanços da tecnologia da informação, os órgãos públicos optam, na maioria das vezes, por divulgar as informações por meio dos portais eletrônicos de transparência. No entanto, essas informações precisam ser úteis, bem como os portais precisam funcionar satisfatoriamente (Silva \& Bruni, 2019). Neste sentido, Raupp \& Pinho (2016) argumentam que, apesar de ter ocorrido um aumento no número de portais de transparência, a informação nem sempre atinge o seu propósito.

Destarte, a transparência pública possibilita, de maneira clara e objetiva, que o cidadão tenha o acesso a informações, seja via relatórios fiscais, portais eletrônicos de transparência, relatórios de gestão anuais, etc. Em suma, a transparência na gestão pública visa objetivar e legitimar as ações praticadas pelos gestores na administração pública, de forma que, por meio da conformidade com a legislação existente, possa reduzir o distanciamento dos administradores perante suas obrigações para com a sociedade.

\subsubsection{Escala Brasil Transparente}

Em comemoração aos três anos de vigência da Lei de Acesso à Informação, Lei $\mathrm{n}^{\circ}$ 12.527/2011, em 16 de maio de 2015, a CGU criou a Escala Brasil Transparente, índice que mede a transparência pública em estados e municípios 
brasileiros. A Escala Brasil Transparente (EBT) é uma metodologia utilizada para fornecer os subsídios necessários ao Ministério da Transparência, Fiscalização e Controladoria Geral da União para o exercício das competências que lhe foram atribuídas (CGU, 2015).

Nesse contexto, o índice EBT avalia o grau de cumprimento de dispositivos da Lei de Acesso à Informação e, atualmente, encontra-se em sua terceira versão. A avaliação do índice está concentrada na transparência passiva e os dados obtidos são disponibilizados a partir de solicitações de acesso à informação aos entes governamentais (CGU, 2015). Em sua metodologia, o índice EBT é composto por quesitos que cobrem aspectos da regulamentação do acesso à informação, a existência e funcionamento do Serviço de Informação ao Cidadão (SIC). De forma geral, a EBT, em seu checklist, avalia os pontos constantes no Quadro 1.

Quadro 1 - Quesitos da Escala Brasil Transparente

\begin{tabular}{|c|c|c|}
\hline Categoria & Quesito avaliado & Peso \\
\hline $\begin{array}{c}\text { I - Regulamentação da } \\
\text { Lei de Acesso }\end{array}$ & $\begin{array}{l}\text { - Exposição da legislação no site do avaliado; } \\
\text { - } \quad \text { Existência da regulamentação; } \\
\text { - Regulamentação do SIC; } \\
\text { - Regulamentação da classificação de sigilo; } \\
\text { - Regulamentação da responsabilização do servidor; } \\
\text { - Regulamentação de instâncias recursais. }\end{array}$ & $25 \%$ \\
\hline $\begin{array}{c}\text { II - Transparência } \\
\text { passiva }\end{array}$ & $\begin{array}{l}\text { - Divulgação do SIC físico (atendimento presencial); } \\
\text { - } \quad \text { Existência de um e-SIC (atendimento pela internet); } \\
\text { - } \quad \text { Inessibilidade de acompanhamento do pedido de acesso; } \\
\text { - Respostas aos pedidos no prazo legal; } \\
\text { - Respostas em conformidade com o que foi solicitado. }\end{array}$ & $75 \%$ \\
\hline
\end{tabular}

Fonte: Elaborado com base em CGU (2018b).

Com a aplicação da EBT, torna-se propício a divulgação de uma métrica, a qual resulta em uma nota que varia de 0 a 10 pontos, em que $25 \%$ da nota é destinada para a regulamentação da Lei de Acesso à Informação e $75 \%$ para a efetiva existência e atuação do e-SIC, o que permite a geração de rankings. A sua análise é do tipo: quanto maior, melhor é o nível de transparência.

Pela metodologia desenvolvida pela CGU, é atribuída a pontuação máxima a toda resposta positiva para cada quesito e zero para as respostas negativas, de modo que a pontuação total obtida pelo município pode variar entre 0 e 3.600 . Para converter essa pontuação para a base 10, foi aplicada a seguinte equação:

$$
\text { Nota }=\frac{\text { Pontuação atingida } \times 10}{3.600}
$$

Desse modo, o indicador permite estabelecer uma comparação entre os municípios, no que diz respeito ao grau de transparência ofertada aos cidadãos, a regulamentação e transparência passiva. O monitoramento da posição em que se encontram os entes avaliados é um fator que permite e incentiva a melhoria do cenário no qual se encontram (CGU, 2015). Portanto, por meio dos resultados obtidos pelos municípios e estados brasileiros, a partir a métrica Escala Brasil Transparente, estes podem ser avaliados, analisados e comparados, além da possibilidade de dar maior visibilidade aos atos públicos.

\section{PROCEDIMENTOS METODOLÓGICOS}

\subsection{Efeito das Características Municipais na Transparência Passiva}

Para explicar as características municipais que condicionam a EBT de 204 municípios mineiros, para o ano de 2016, o modelo econométrico empregado, neste estudo, é o Tobit. O modelo Tobit, originalmente formulado por James Tobin, também é conhecido como regressão censurada (Gujarati \& Porter, 2011). O modelo de regressão no qual a variável dependente assume valores em dado limite, com concentração de valores iguais ao limite, consiste em modelo cuja amostra é censurada, como é o caso da variável dependente do presente estudo, tendo em vista a sua variação entre 0 e 10 .

Diante do exposto, para identificar os fatores econômicos, financeiros e sociais que possam interferir na transparência passiva, foi utilizada a metodologia de dados em corte transversal para os municípios mineiros abrangidos pela EBT, conforme equação a seguir: 


$$
E B T_{i}=\beta+\alpha X_{i}+\theta D \operatorname{Reg}_{i}+\mu_{i}
$$

$\mathrm{i}=1, \ldots, 204$ municípios

em que $E B T_{\mathrm{i}}$ representa uma variável proxy para a transparência pública passiva de 204 municípios de Minas Gerais; $X_{\mathrm{i}}$ é o vetor de variáveis econômicas, financeiras e sociais; $D R e g_{\mathrm{i}}$ são dummies que visam a captar as características regionais; $\beta, \alpha$ e $\theta$ são os parâmetros a serem estimados; $\mu$ é o erro aleatório.

O Quadro 2 apresenta um resumo das variáveis utilizadas para explicar a transparência pública municipal.

Quadro 2 - Descrição das varáveis explicativas inseridas no modelo

\begin{tabular}{|c|c|c|c|}
\hline Variável & Descrição & $\begin{array}{c}\text { Efeito } \\
\text { Esperado }\end{array}$ & Base teórica \\
\hline $\operatorname{DReg}_{i}$ & $\begin{array}{c}\text { Dummies regionais: agrupam os municípios } \\
\text { conforme a classificação do Serviço Brasileiro de } \\
\text { Apoio às Micro e Pequenas Empresas (SEBRAE), } \\
\text { assumindo valor } 1 \text { se o município pertence a dada } \\
\text { região e, zero, caso contrário }\end{array}$ & $-/+$ & $\begin{array}{l}\text { Baldissera, Dall'Asta, Casagrande \& } \\
\text { Oliveira (2020) e Quintela (2011) }\end{array}$ \\
\hline PIBpc $_{i}$ & Produto Interno Bruto per capita & + & $\begin{array}{l}\text { W. A. de O. Silva (2017), Melo et al. (2016), } \\
\text { Caba Perez, Rodríguez Bolívar \& López } \\
\text { Hernández (2014), Rossoni (2013) e Cruz, } \\
\text { Ferreira, Silva \& Macedo (2012) }\end{array}$ \\
\hline$E S C p o p_{i}$ & $\begin{array}{l}\text { Escolaridade da População acima de } 25 \text { anos, com } \\
\text { ensino médio completo ou superior completo }\end{array}$ & + & $\begin{array}{c}\text { Sun \& Andrews (2020), W. A. de O. Silva } \\
\text { (2017), Caba Perez et al. (2014), Cruz et al. } \\
\text { (2012) e Serrano-Cinca, Rueda-Tomás \& } \\
\text { Portillo-Tarragona (2009) }\end{array}$ \\
\hline$I F D M_{i}$ & Índice Firjan de Desenvolvimento Municipal & + & $\begin{array}{l}\text { Pereira et al. (2020), Melo et al. (2016), } \\
\text { Zuccolotto \& Teixeira (2014), Rossoni } \\
\text { (2013) e Cruz et al. (2012) }\end{array}$ \\
\hline$I D G M_{i}$ & Idade do Gestor Municipal & - & $\begin{array}{c}\text { Silva \& Bruni (2019) e W. A. de O. Silva } \\
\text { (2017) }\end{array}$ \\
\hline$R E C p c_{i}$ & Receita Bruta per capita & + & $\begin{array}{l}\text { W. A. de O. Silva (2017), Melo et al. (2016), } \\
\text { Muñoz, Bolívar \& Hernández (2016), } \\
\text { Zuccolotto \& Teixeira (2014), Rossoni } \\
\text { (2013) e Cruz et al. (2012) }\end{array}$ \\
\hline
\end{tabular}

Fonte: Elaborado pelos autores.

\subsection{Fonte e Tratamento dos Dados}

A amostra da presente pesquisa é constituída por 204 municípios mineiros que foram avaliados pela CGU na $3^{\mathrm{a}}$ edição do Índice Escala Brasil Transparente, no ano de 2016. Os dados do índice EBT foram coletados junto ao portal da CGU (2018c).

$\mathrm{Na}$ análise descritiva dos dados, os municípios foram agrupados em quatro categorias, de acordo com as notas da EBT, como pode ser visualizado na Tabela 1.

Tabela 1 - Agrupamento dos municípios conforme a escala de transparência

\begin{tabular}{c|c|c}
\hline Descrição & Escala de transparência & Total de municípios analisados \\
\hline Sem transparência & 0 & 63 \\
Baixa & $0,55-4,99$ & 97 \\
Média & $5-7,99$ & 27 \\
Alta & $8-10$ & $\mathbf{2 0 4}$ \\
Total & & 17
\end{tabular}

Fonte: Elaborada segundo dados da CGU (2018c). 
A construção das dummies regionais foi realizada a partir de dados obtidos junto ao Sebrae (2018). O PIB per capita e a Escolaridade da População acima de 25 anos, com ensino médio completo ou superior completo, foram coletados no site do Instituto Brasileiro de Geografia e Estatística [IBGE] (2016). Já a fonte de coleta de dados do Índice Firjan de Desenvolvimento Municipal foi a Federação da Indústria do Estado do Rio de Janeiro (Firjan) (2018). Por sua vez, a Idade do Gestor Municipal foi obtida no Tribunal Superior Eleitoral [TSE] (2016), enquanto a Receita Orçamentária foi extraída da Secretaria do Tesouro Nacional [STN] (2019).

As variáveis monetárias PIB e Receita Orçamentária tratam de valores anuais, por habitante, expressos em reais, referente ao ano de 2016.

\section{RESULTADOS}

\subsection{Caracterização dos Municípios Abrangidos pelo Índice EBT}

O estado de Minas Gerais é formado por 853 municípios, sendo que, destes, são analisadas 204 cidades que apresentam dados tanto da EBT quanto das demais variáveis inseridas no modelo, para o ano de 2016. Este total representa aproximadamente $24 \%$ dos municípios mineiros.

Na Tabela 2, é apresentada a estatística descritiva da EBT, considerando a totalidade dos municípios abrangidos pelo índice na $3^{\mathrm{a}}$ edição (coluna a) e apenas os municípios que mostraram algum nível de transparência (coluna b).

Tabela 2 - Estatística descritiva da EBT

\begin{tabular}{c|c|c}
\hline Descrição & Total de municípios analisados (a) & Municipios que receberam pontuação (b) \\
\hline Média & 2,73 & 3,95 \\
Desvio Padrão & 2,88 & 2,64 \\
Mínimo & 0 & 0,55 \\
Máximo & 10 & 10 \\
Total & $\mathbf{2 0 4}$ & $\mathbf{1 4 1}$ \\
\hline
\end{tabular}

Fonte: Elaborada segundo dados do CGU (2018c).

Pela Tabela 2, verifica-se que o escore médio do total de municípios analisados (204) é de 2,73, variando entre 0 (valor mínimo) e 10 (valor máximo). Os municípios considerados transparentes, que receberam pontuação no índice (141), têm média de 3,95, oscilando entre 0,55 e 10 .

O desvio padrão do total de municípios analisados é de 2,88, enquanto para os municípios que receberam notas, é de 2,64. Observa-se que o desvio padrão dos municípios da amostra é mais distante da média do que o daqueles considerados transparentes. Isso ocorre devido ao fato de a amostra ter muitos municípios com notas zeradas.

Em geral, os municípios analisados apresentam baixos níveis de transparência passiva, visto que, dos 204 municípios analisados, 63 receberam nota zero. Assim, em torno de $31 \%$ dos entes não possuem nenhuma ferramenta de disponibilização de informações e, consequentemente, estão em descumprimento com a Lei $n^{\circ} 12.527 / 2011$. Cabe destacar que, desses 63 municípios, cerca de $76 \%$ têm menos de dez mil habitantes.

Segundo o artigo $8^{\circ}$ da Lei $n^{\circ} 12.527 / 2011$, é dever dos órgãos e entidades públicas promover, independentemente de requerimentos, a divulgação em local de fácil acesso, de informações de interesse coletivo ou geral por eles produzidas ou custodiadas. Além disso, seu parágrafo $4^{\circ}$ evidencia que os municípios com população de até dez mil habitantes ficam dispensados da divulgação obrigatória na internet, mas é mantida a obrigatoriedade de divulgação, em tempo real, de informações relativas à execução orçamentária e financeira, observando os critérios e prazos estabelecidos.

$\mathrm{Na}$ Tabela 3, consta um agrupamento dos municípios, de acordo com a nota da EBT, em quatro categorias - sem transparência, baixo, médio e alto/melhor nível de transparência -, bem como os valores médios de algumas características das cidades analisadas.

Conforme a Tabela 3, os municípios considerados não transparentes (nota zero) totalizam 63, o segundo maior grupo. Esse grupo apresenta o menor PIB per capita médio, no valor de R\$14.072,17, menor proporção de pessoas com ensino médio e superior completo $(0,19)$, gestores mais jovens, com idade média de, aproximadamente, 48 anos, e municípios com nível de desenvolvimento médio inferior às demais categorias analisadas. Por outro lado, os municípios que não atendem aos requisitos da Lei da Transparência e da Lei de Acesso à Informação possuem uma melhor receita orçamentária por habitante, o que pode levar a acreditar que o nível arrecadatório não tem relação direta com o grau de transparência.

A categoria denominada baixa transparência (nota 0,55 a 4,99) contempla 97 municípios, que representam 47,54 $\%$ das prefeituras da amostra, maior grupo (Tabela 1). Estas cidades apresentam o maior PIB per capita médio, no valor de $\mathrm{R} \$ 20.189,79$, e segunda maior receita orçamentária per capita média, de $\mathrm{R} \$ 3.429,92$. Percebe-se que a maioria das cidades mineiras analisadas está classificada com baixo nível de transparência, representando 11,37\% do total de municípios do estado de Minas Gerais. 
Os municípios classificados em média transparência (nota 5,00 a 7,99) correspondem a 13,23\% das prefeituras da amostra, terceiro maior grupo. Estes municípios têm o segundo maior PIB per capita médio, no valor de R\$19.194,65, e receita orçamentária média de $\mathrm{R} \$ 3.129,12$.

Por fim, os municípios considerados com alto nível de transparência (nota 8,00 a 10) possuem uma representatividade de $8,33 \%$ das prefeituras municipais da amostra. Esse grupo apresenta a menor receita orçamentária per capita média, no valor de $\mathrm{R} \$ 2.908,47$, a maior proporção de pessoas com ensino médio e superior completo $(0,28)$, gestores com idade mais elevada, com idade média de, aproximadamente, 55 anos, e o melhor nível de desenvolvimento médio em relação às demais categorias analisadas. Nota-se que as cidades com melhores níveis de transparência possuem população com maior nível de instrução que as demais, o que pode levar a acreditar que a escolaridade da população tem relação direta com o grau de transparência, e que gestores mais maduros tendem a ser mais transparentes em suas ações em comparação com aqueles de menor idade.

Tabela 3 - Categorização dos municípios de acordo com a nota da EBT

\begin{tabular}{|c|c|c|c|c|c|c|}
\hline \multicolumn{2}{|r|}{ Categorias } & \multirow{2}{*}{$\begin{array}{c}\begin{array}{c}\text { Sem } \\
\text { Transp. }\end{array} \\
0\end{array}$} & \multirow{2}{*}{$\begin{array}{c}\text { Baixa } \\
0,55-4,99\end{array}$} & \multirow{2}{*}{$\begin{array}{c}\text { Média } \\
5,00-7,99\end{array}$} & \multirow{2}{*}{$\begin{array}{c}\text { Alta } \\
8,00-10\end{array}$} & \multirow{2}{*}{$\begin{array}{c}\text { Média } \\
\text { Amostral }\end{array}$} \\
\hline & Nota & & & & & \\
\hline \multirow{6}{*}{ 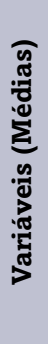 } & PIB per capita & $14.072,17$ & $20.189,79$ & $19.194,65$ & $19.966,54$ & $18.150,21$ \\
\hline & Escolaridade da População & 0,19 & 0,20 & 0,23 & 0,28 & 0,20 \\
\hline & IFDM & 0,66 & 0,68 & 0,71 & 0,72 & 0,68 \\
\hline & Idade do Gestor Municipal & 47,94 & 51,73 & 52,44 & 54,88 & 50,91 \\
\hline & Receita Orç. per capita & $3.563,49$ & $3.429,92$ & $3.129,12$ & $2.908,47$ & $3.387,90$ \\
\hline & População & $9.395,69$ & $23.106,38$ & $31.293,33$ & $211.708,70$ & $35.672,63$ \\
\hline \multirow{8}{*}{ 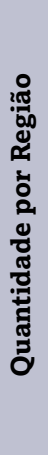 } & Centro & 8 & 15 & 10 & 5 & 38 \\
\hline & Jequitinhonha/Mucuri & 5 & 7 & 1 & 1 & 14 \\
\hline & Noroeste & 2 & 3 & 0 & 0 & 5 \\
\hline & Norte & 13 & 8 & 0 & 0 & 21 \\
\hline & Rio Doce & 3 & 17 & 2 & 0 & 22 \\
\hline & Sul & 14 & 22 & 9 & 7 & 52 \\
\hline & Triângulo & 3 & 10 & 0 & 0 & 13 \\
\hline & Zona da Mata & 15 & 15 & 5 & 4 & 39 \\
\hline \multicolumn{2}{|r|}{ Total } & 63 & 97 & 27 & 17 & 204 \\
\hline
\end{tabular}

Fonte: Resultados da pesquisa.

Com base nas categorias de transparência estabelecidas (Tabela 3), em relação à receita orçamentária per capita, percebe-se que municípios com alta transparência apresentam menor receita orçamentária por habitante ( $\mathrm{R} \$ 2.908,47)$ do que os municípios considerados não transparentes ( $\mathrm{R} \$ 3.563,49)$. O resultado encontrado diverge dos estudos anteriores, como W. A. de O. Silva (2017), Melo et al. (2016) e Cruz et al. (2012), que afirmam que municípios com maior eficiência relativa na arrecadação de receitas tendem a divulgar mais informações em meio eletrônico de acesso público.

A variável Índice Firjan de Desenvolvimento Municipal (IFDM) acompanha o desenvolvimento socioeconômico dos municípios brasileiros, com base nas três áreas fundamentais ao desenvolvimento humano: educação, saúde e emprego e renda. Nota-se que essa variável, na análise, se mantém praticamente constante, sendo que a diferença entre o IFDM dos municípios considerados não transparentes e aqueles com alto nível de transparência é apenas de 0,06 (com valor mínimo de 0,66 e máximo de 0,72). Em comparação com a média amostral do referido índice, pode-se observar que os municípios classificados com média e alta transparência possuem médias superiores à amostral, de 0,68, fato este que não pode ser observado para os outros dois grupos.

Ao analisar a receita orçamentária média da amostra, é interessante observar que os municípios considerados não transparentes e aqueles com baixo grau de transparência são os que apresentam receita orçamentária superiores à média dos 204 municípios analisados. No caso do PIB per capita, que obteve média amostral de R $\$ 18.150,21$, esta é maior apenas que o PIB dos entes considerados não transparentes.

Quanto às regiões do estado de Minas Gerais, a distribuição dos municípios da amostra se dá da seguinte forma: 52 estão na região Sul, 39 na Zona da Mata, 38 na região Centro, 22 na região do Rio Doce, 21 na do Norte, 14 na do Jequi- 
tinhonha/Mucuri, 13 na do Triângulo e 5 na região Noroeste do estado. Na sequência, a Figura 1 mostra a distribuição dos municípios de acordo com as regiões e categorias de transparência.

Figura 1 - Quantidade de municípios com base nas regiões e categorias de transparência

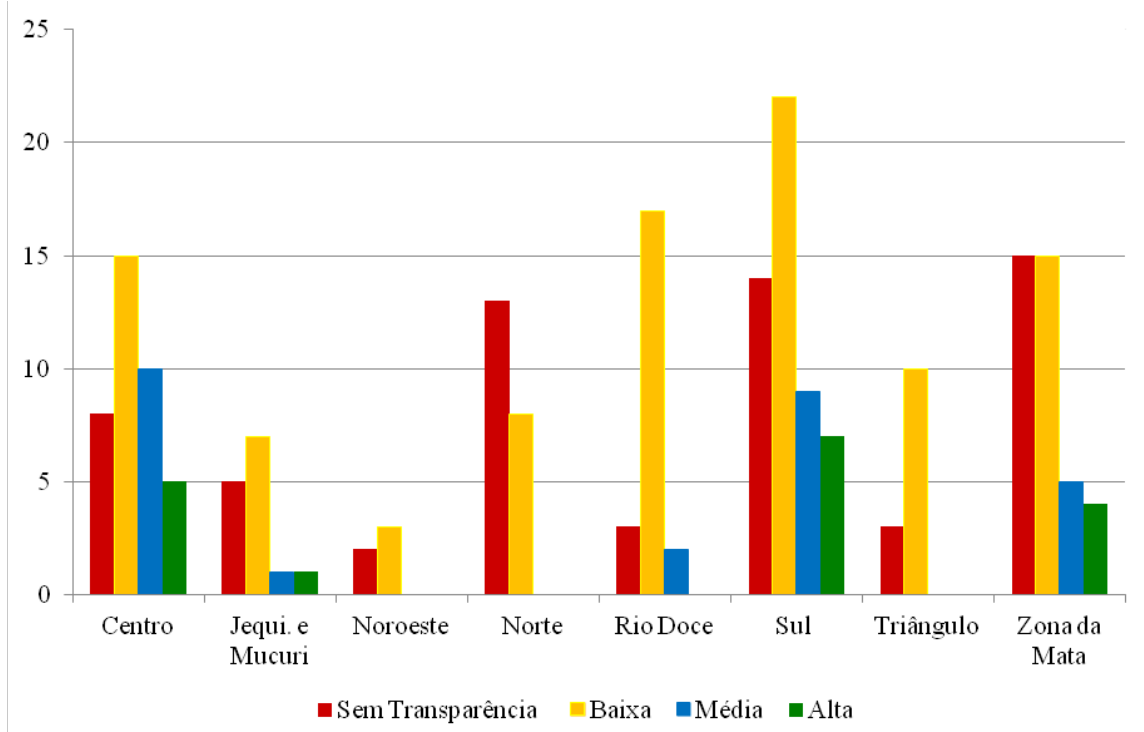

Fonte: Resultados da pesquisa.

Pela Figura 1, pode-se visualizar que as regiões Noroeste, Norte e Triângulo não exibem nenhum município com médio nível de transparência e, além dessas regiões, também a região do Rio Doce não possui nenhum município com alto nível de transparência. No caso da do Rio Doce, a maioria dos municípios da amostra apresenta baixo nível de transparência.

Considerando os melhores resultados (nota 8 a 10) com relação à escala de nível de transparência, as regiões que se destacam são: Sul (7 municípios), Centro (5), Zona da Mata (4) e Jequitinhonha/Mucuri (1). Já os municípios que tiveram pior resultado em termos de transparência estão situados nas regiões: Zona da Mata (15 municípios), Sul (14), Norte (13) e Centro (8). Nota-se que, apesar da região Sul estar localizada em uma área geográfica com melhor desenvolvimento, esta possui mais municípios sem transparência do que com alto nível.

\subsection{Fatores Determinantes da Transparência Passiva}

Para identificar os fatores determinantes da transparência passiva nos municípios mineiros contemplados pelo índice de transparência calculado pela CGU, efetua-se a estimação do modelo Tobit, que é considerado eficiente para estimar a relação entre a variável dependente censurada, ou truncada, e as variáveis explicativas. Neste caso, busca-se analisar a dependência estatística entre o índice EBT, proxy para a transparência passiva, e características municipais de uma amostra de 204 cidades mineiras. Destaca-se que a transparência passiva ocorre quando o cidadão solicita a informação a algum órgão ou ente público (sem que este seja obrigado por lei a publicá-la), desde que não sejam resguardadas por sigilo.

No modelo estimado, além de variáveis como PIB e receita orçamentária por habitante, idade do prefeito, nível de desenvolvimento de cada município e escolaridade populacional, são incluídas dummies para cada região do estado de Minas Gerais. A inclusão dessas últimas variáveis visa controlar as características/especificidades regionais no que se refere às questões socioeconômicas, demográficas e institucionais. Os resultados da estimação do modelo podem ser visualizados na Tabela 4.

Tabela 4 - Fatores associados à transparência passiva dos municípios mineiros

\begin{tabular}{c|c|c|c}
\hline Variáveis & Coeficientes & Erro Padrão & p-Valor \\
\hline Idade do Gestor Municipal & $0,0616^{\star \star}$ & 0,02608 & 0,019 \\
Índice Firjan de Desenvolvimento Municipal & $10,8301^{\star \star}$ & 4,8814 & 0,028 \\
PIB per capita & $0,00004^{\star \star \star}$ & 0,00001 & 0,004 \\
Receita Orçamentária per capita & $-0,0004^{\star \star}$ & 0,0002 & 0,011 \\
Escolaridade da população & $9,6103^{\star \star}$ & 4,0886 & 0,020
\end{tabular}




\begin{tabular}{c|c|c|c}
\hline Variáveis & Coeficientes & Erro Padrão & p-Valor \\
\hline Dummy Jequitinhonha/Mucuri & $0,8474^{\mathrm{NS}}$ & 1,4612 & 0,563 \\
Dummy Noroeste & $-4,2798^{\star \star \star}$ & 1,4558 & 0,004 \\
Dummy Norte & $-2,6447^{\star \star}$ & 1,1237 & 0,020 \\
Dummy Rio Doce & $-0,1420^{\mathrm{NS}}$ & 0,7901 & 0,858 \\
Dummy Sul & $-1,3153^{\star}$ & 0,7678 & 0,088 \\
Dummy Triângulo & $-3,7425^{\star \star \star}$ & 0,9026 & 0,000 \\
Dummy Zona da Mata & $-1,2446^{\mathrm{NS}}$ & 0,8862 & 0,162 \\
Constante & $-8,8160^{\star \star}$ & 3,5045 & 0,013 \\
\hline
\end{tabular}

Fonte: Resultados da pesquisa.

Notas: i. ${ }^{* * \star}$ Significativo a $1 \%$; ${ }^{* \star S i g n i f i c a t i v o ~ a ~} 5 \%$; 'Significativo a $10 \%$; NS: não significativo. ii. Estimação com correção pelo erro padrão robusto, de modo a atender ao pressuposto de homocedasticidade. iii. A região de controle foi a denominada Centro.

A partir do modelo estimado, conforme Tabela 4, o coeficiente da variável Idade do Gestor Municipal (IDGM) foi estatisticamente significativo a $5 \%$ e positivo, indicando que o aumento na idade do prefeito contribui para melhorar o nível de transparência passiva dos municípios, mantidas as demais variáveis constantes. Esse resultado difere daquele encontrado por W. A. de O. Silva (2017) para os municípios brasileiros, que foi efeito negativo e não significativo. Uma possível explicação para o impacto positivo dessa variável pode estar associada ao fato de o prefeito com idade mais elevada possuir maior grau de experiência e uma conscientização de que os preceitos das leis devem ser observados.

A variável Índice Firjan de Desenvolvimento Municipal (IFDM) também apresentou resultado significativo a 5\% e positivo, mostrando que o desenvolvimento municipal tem relação direta com o grau de transparência passiva dos entes públicos analisados. O referido achado é similar aos resultados dos trabalhos de Melo et al. (2016), Zuccolotto \& Teixeira (2014), Rossoni (2013) e Cruz et al. (2012), ao identificarem que municípios com melhores índices de desenvolvimento tendem a possuir melhores níveis de transparência passiva.

O coeficiente do Produto Interno Bruto per capita (PIBPC) foi estatisticamente significativo a 1\%, evidenciando que um incremento na riqueza municipal por indivíduo faz com que o nível de transparência passiva se eleve, excluindo os possíveis efeitos das outras variáveis inseridas no modelo. Resultado similar foi encontrado nos trabalhos de W. A. de O. Silva (2017), Melo et al. (2016), Caba Perez et al. (2014), Rossoni (2013) e Cruz et al. (2012).

Ao analisar o coeficiente da Receita Orçamentária per capita (RECPC), constata-se significância estatística a 5\%, porém, com sinal negativo, indicando que um aumento na capacidade de arrecadação municipal por indivíduo contribui para uma queda no nível de transparência passiva, mantidas as demais variáveis constantes. O resultado encontrado foi diferente das pesquisas de W. A. de O. Silva (2017), Melo et al. (2016), Zuccolotto \& Teixeira (2014), Rossoni (2013) e Cruz et al. (2012). Esses achados estatísticos da receita orçamentária, na presente pesquisa, vão ao encontro da capacidade financeira dos municípios evidenciada na Tabela 3, em que os entes públicos com melhores níveis de transparência dispõem de menores receitas orçamentarias médias.

O resultado do coeficiente da Escolaridade da População (RECPC) foi estatisticamente significativo a 5\%, com sinal positivo. Isso evidencia que o aumento na escolaridade dos indivíduos colabora para que o município seja mais transparente. Conforme os trabalhos de W. A. de O. Silva (2017) e Cruz et al. (2012), uma população com maior grau de instrução tende a ser mais enérgica com relação aos atos da administração pública, buscando mais informações.

Ao observar as dummies, as representativas das regiões do Jequitinhonha/Mucuri, Rio Doce e Zona da Mata não foram estatisticamente significativas. Esse achado conduz à ideia de que suas especificidades regionais são similares às da região Centro, no que se refere ao efeito dessas variáveis sobre a transparência passiva. Porém, no caso da dummy Jequitinhonha/Mucuri, esperava-se um resultado contrário, uma vez que as características econômicas e sociais dos municípios que a compõem podem ser bem distintas da região de referência (Centro).

Os coeficientes das dummies das regiões Noroeste, Norte, Sul e Triângulo se mostraram significativos para explicar o resultado da transparência passiva dos municípios mineiros analisados. Considerando que a região de referência foi a Centro, esse resultado evidencia que o fato de pertencer a qualquer uma dessas outras regiões do estado de Minas Gerais faz com que o nível de transparência passiva municipal seja reduzido. Isso mostra que as características distintas de uma região para a outra influenciam no resultado da transparência dos municípios.

\section{CONSIDERAÇÕES FINAIS}

Tendo em vista que a pesquisa buscou verificar quais características municipais podem influenciar o nível de transparência dos municípios do estado de Minas Gerais, utilizando a métrica Escala Brasil Transparente, constatou-se que as variáveis PIB per capita, idade do gestor municipal, Índice Firjan de Desenvolvimento Municipal e escolaridade da 
população contribuem de forma positiva para explicar o nível de transparência passiva dos municípios mineiros analisados. Assim, municípios com maior renda per capita e desenvolvimento municipal, prefeituras com gestores com idade mais elevada e população com maior nível de instrução, tendem a apresentar melhores níveis de transparência passiva.

Por outro lado, a receita orçamentária per capita apresentou um relacionamento significativo, porém, com efeito negativo, indicando que municípios com melhor receita orçamentária por habitante tendem a ser menos transparentes. Isso pode ser explicado pelo fato de, no presente estudo, o índice de transparência analisado medir a divulgação de informações pelo ente público quando este é provocado pelo cidadão, e não a publicação de forma voluntária como ocorre com a transparência ativa.

Com relação às dummies regionais, as representativas do Jequitinhonha/Mucuri, Rio Doce e Zona da Mata não tiveram significância estatística, no entanto, nas demais, verificou-se um relacionamento significativo, indicando que as diferentes características econômicas e sociais dos municípios influenciam na transparência pública passiva.

De maneira geral, os resultados apontaram que os munícipios mineiros investigados apresentaram baixos níveis de transparência pública passiva. Esse fato pode estar relacionado com fatores econômicos como, por exemplo, a baixa capacidade financeira, prejudicando ou retardando o investimento em tecnologias, tais como aquisição de equipamentos ou softwares para atendimento das solicitações de informações. Além disso, é preciso que haja servidores capacitados para desempenharem demandas específicas ligadas à transparência passiva.

Adicionalmente, pode-se atribuir esse baixo nível de transparência passiva a fatores regionais, devido às diferenças territoriais entre cidades com melhor ou pior desenvolvimento, necessitando da revisão de políticas de descentralização do poder, de modo a discutir meios de investimentos, no sentido de diminuir as disparidades em termos de desenvolvimento.

Pelos resultados, há evidências de que a escolaridade da população constitui um fator decisivo para melhores resultados da gestão pública municipal, pois quanto maior for o nível de instrução da população, mais próxima a sociedade estará da máquina pública, cumprindo seu papel de cidadão participativo e fiscalizador.

Como limitação da pesquisa, menciona-se o fato de a análise ter sido pautada em uma pequena amostra, apenas 204 municípios mineiros. Outra limitação diz respeito à análise de dados em seção cruzada, ou seja, os determinantes da transparência pública dos municípios em dado ano, não sendo possível fazer inferências ou comparações temporais.

Portanto, para trabalhos futuros, sugere-se uma análise dos determinantes da transparência passiva dos municípios brasileiros e de dados por um determinado período, para verificar o comportamento das variáveis ao longo do tempo.

\section{REFERÊNCIAS}

Araujo, J. F. F. E., \& Romero, F. T. (2016). Local government transparency index: determinants of municipalities' rankings. Internacional Journal of Public Sector Management, 29(4), 327-347.

Bairral, M. A. C., Silva, A. H. C., \& Alves, F. J. dos S. (2015). Transparência no setor público: uma análise dos relatórios de gestão anuais de entidades públicas federais no ano de 2010. Revista de Administração Pública, 49 (3), 643-675. http://dx.doi.org/10.1590/00347612125158

Baldissera, J. F., Dall'Asta, D., Casagrande, L. F., \& Oliveira, A. M. B. de. (2020). Influência dos aspectos socioeconômicos, financeiro-orçamentários e político-eleitorais na transparência dos governos locais. Revista de Administração Pública, 54(2), 340-359. https:// dx.doi.org/10.1590/0034-761220190048

Caba Perez, M. D. C., Rodríguez Bolívar, M. P., \& López Hernández, A. M. (2014). The determinants of government financial reports online. Transylvanian Review of Administrative Sciences, (42), 5-31.

Constituição da República Federativa do Brasil de 1988. (1988). Brasília, DF. Recuperado de http://www.planalto.gov.br/ccivil_03/ constituicao/constituicaocompilado.htm

Controladoria Geral da União (2015). CGU lança indice que mede transparência de estados e municípios. Recuperado em 8 dezembro, 2018, de http://www.cgu.gov.br/noticias/2015/05/cgu-lanca-indice-que-mede-transparencia-de-estados-e-municipios

Controladoria Geral da União (2018b). Escala Brasil Transparente - Dados abertos. Recuperado em 12 outubro, 2018, de http:// www.cgu.gov.br/dados-abertos/arquivos/ebt

Controladoria Geral da União (2018c). Escala Brasil Transparente - Panorama dos Governos Municipais - Minas Gerais. Recuperado em 20 outubro, 2018, de https://relatorios.cgu.gov.br/Visualizador.aspx?id_relatorio=23

Controladoria Geral da União (2013). Manual da Lei de Acesso à Informação para Estados e Municípios. Recuperado em 24 fevereiro, 2019, de https://www.cgu.gov.br/Publicacoes/transparencia-publica/brasil-transparente/arquivos/manual_lai_estadosmunicipios.pdf

Controladoria Geral da União (2018a). Papel da CGU. Recuperado em 28 fevereiro, 2019, de https://www.cgu.gov.br/assuntos/ etica-e-integridade/conflito-de-interesses/papel-da-cgu

Cruz, C. F., Ferreira, A. C. de S., Silva, L. M. da, \& Macedo, M. A. da S. (2012). Transparência da Gestão Pública Municipal: um estudo a partir dos portais eletrônicos dos maiores municípios brasileiros. Revista de Administração Pública, 46(1), 153-176. http://dx.doi. org/10.1590/S0034-76122012000100008

Federação da Indústria do Estado do Rio de Janeiro (2018). IFDM: Índice Firjan de Gestão Fiscal. Recuperado em 15 fevereiro, 2019 de https://www.firjan.com.br/ifdm/

Gujarati, D. N., \& Porter, D. C. (2011). Econometria Básica. (5a ed.). Porto Alegre, RS: Editora Mc Graw Hill. 
Instituto Brasileiro de Geografia e Estatística (2016). Estatísticas. Recuperado em 5 maio, 2019, de https://downloads.ibge.gov.br/ downloads_estatisticas.htm

Lacerda, S. M. de P., Helal, D. H., \& Cabral, S. de M. (2017, novembro). O Governo Aberto e o seu princípio: a transparência. Anais do Encontro Brasileiro de Administração Pública, João Pessoa, PB, Brasil, 4.

Lei Complementar n. 101, de 04 de maio de 2000. (2000). Estabelece normas de finanças públicas voltadas para a responsabilidade na gestão fiscal e dá outras providências. Brasília, DF. Recuperado de http://www.planalto.gov.br/CCivil_03/Leis/LCP/Lcp101.htm

Lei Complementar n. 131, de 27 de maio de 2009. (2009). Acrescenta dispositivos à Lei Complementar $n^{\circ} 101$, de 04 de maio de 2000, que estabelece normas de finanças públicas voltadas para a responsabilidade na gestão fiscal e dá outras providências, a fim de determinar a disponibilização, em tempo real, de informações pormenorizadas sobre a execução orçamentária e financeira da União, dos Estados, do Distrito Federal e dos Municípios. Brasília, DF. Recuperado de http://www.planalto.gov.br/ccivil_03/LEIS/ LCP/Lcp131.htm

Lei $n$. 12.527, de 18 de novembro de 2011. (2011). Regula o acesso a informações previsto no inciso XXXIII do art. 5o, no inciso II do $\S 3$ o do art. 37 e no $\S 20$ do art. 216 da Constituição Federal; altera a Lei no 8.112, de 11 de dezembro de 1990; revoga a Lei no 11.111, de 05 de maio de 2005, e dispositivos da Lei no 8.159, de 8 de janeiro de 1991; e dá outras providências. Brasília, DF. Recuperado de http://www.planalto.gov.br/ccivil_03/_ato2011-2014/2011/lei/l12527.htm

Leite, G. A. F., Colares, A. F. V., \& Andrade, I. C. F. (2015). Transparência da Gestão Fiscal Pública: um estudo a partir dos portais eletrônicos dos maiores municípios do estado de Minas Gerais. Contabilidade Vista \& Revista, 26(2), 114-136. Recuperado em 11 janeiro, 2019, de file:///D:/bkp/Downloads/2647-Texto\%20do\%20artigo-10073-1-10-20150824\%20(1).pdf

Loureiro, M. R., Teixeira, M. A. C., \& Prado, O. (2008). Construção de instituições democráticas no Brasil contemporâneo: transparência das contas públicas. Revista Organização \& Sociedade, 15(47). Recuperado em 14 dezembro, 2018, de https://portalseer.ufba. $\mathrm{br} /$ index.php/revistaoes/article/view/10985/7908

Melo, K. B. de, Martins, G. A., \& Martins, V. F. (2016). Análise do nível de transparência dos websites dos municípios mineiros. Revista de Auditoria, Governança e Contabilidade, 4(9), 93-111. Recuperado em 20 abril, 2019, de http://www.fucamp.edu.br/editora/ index.php/ragc/article/view/665

Muñoz, L. A., Bolívar, M. P. B., \& Lopez Hernández, A. M. L. (2017). Transparency in governments: a meta-analytic review of incentives for digital versus hard-copy public financial disclosures. American Review of Public Administration, 47(5), 550-573.

Pereira, J. P. do N., Pereira, D. M. V. G., \& Morais, J. J. da S. (2020, julho). Determinantes da Transparência Pública nos Municípios Brasileiros: um estudo sobre a relação entre o Índice de Desenvolvimento Humano e a Escala Brasil Transparente. Anais do Congresso USP de Iniciação Cientifica em Contabilidade, São Paulo, SP, Brasil, 7.

Possamai, A. J., \& Souza, V. de G. (2020). Transparência e dados abertos governamentais: possibilidades e desafios a partir da lei de acesso à informação. Administração Pública e Gestão Social, 12(2). https://doi.org/10.21118/apgs.v12i2.5872

Quintela, M. C. de A. (2011). Gasto público social dos estados brasileiros: um estudo sob a ótica da eficiência técnica. Tese de doutorado, Universidade Federal de Viçosa, Viçosa, MG. Recuperado em 4 abril, 2019, de http://www.locus.ufv.br/bitstream/handle/123456789/146/textocompleto.pdf?sequence=1\&isAllowed=y

Raupp, F. M. (2016). Realidade da transparência passiva em prefeituras dos maiores municípios brasileiros. Revista Contemporânea de Contabilidade, 13(30), 34-52. http://dx.doi.org/10.5007/2175-8069.2016v13n30p34

Raupp, F. M., \& Pinho, J. A. G. (2016). Review of passive transparency in Brazilian city councils. Public Management, 51(3), $288-298$. https://doi.org/10.1016/j.rausp.2016.02.001

Rossoni, F. V. (2013). Transparência na Gestão Pública Municipal: uma análise nos sitios eletrônicos das Prefeituras Municipais do Estado do Espirito Santo. Dissertação de mestrado, Fundação Instituto Capixaba de Pesquisas em Contabilidade, Economia e Finanças, Vitória, ES. Recuperado em 1 abril, 2019, de file:///D:/bkp/Downloads/Dissertacao\%20Fabiana\%20Venturini\%20Rossoni.pdf

Secretaria do Tesouro Nacional (2019). Siconfi: Sistema de Informações Contábeis e Fiscais do Setor Público Brasileiro. Recuperado em 16 maio, 2019, de https://siconfi.tesouro.gov.br/siconfi/pages/public/consulta_finbra/finbra_list.jsf

Serrano-Cinca, C., Rueda-Tomás, M., \& Portillo-Terragona, P. (2009). Factors influencing e-disclosure in local public administrations. Environment and Planning C: Government and Policy, 27, 355-378.

Serviço Brasileiro de Apoio às Micro e Pequenas Empresas (2018). Dados e Pesquisas: Identidade dos Municipios. Recuperado em 15 maio, 2019, de https://www.sebraemg.com.br/atendimento/conteudo/dados-e-pesquisas/identidade-dos-municipios

Silva, L. M. da. (2009). Contabilidade Governamental: um enfoque administrativo. (8a ed.). São Paulo: Atlas.

Silva, W. A. de O. (2017). Variáveis determinantes para a transparência pública passiva nos municipios brasileiros. Dissertação de mestrado, Universidade Federal da Bahia, Salvador, BA. Recuperado em 4 janeiro, 2019, de https://repositorio.ufba.br/ri/bitstream/ ri/24245/1/Disserta\%c3\%a7\%c3\%a3o\%20de\%20Mestrado\%20-\%20Walber\%20Alexandre\%20de\%20Oliveira\%20e \%20Silva.pdf

Silva, W. A. de O., \& Bruni, A. L. (2019). Variáveis socioeconômicas determinantes para a transparência pública passiva nos municípios brasileiros. Revista de Administração Pública, 53 (2), 415-431. Recuperado em 22 fevereiro, 2021, de https://doi.org/10.1590/0034761220170383

Silveira, M. A. K. (2012). Lei de acesso a informações públicas (Lei $\mathrm{n}^{\circ}$ 12.527/2011): democracia, república e transparência no Estado Constitucional. Revista da Procuradoria Geral do Estado, 33(69), 231-260. Recuperado em 29 junho, 2019, de https://www.pge. rs.gov.br/upload/arquivos/201703/22165826-rpg69livro.pdf.

Sun S., \& Andrews, R. (2020). The determinants of fiscal transparency in Chinese city-level governments, Local Government Studies, 46(1), 44-67. https://doi.org/10.1080/03003930.2019.1608828 
Tribunal Superior Eleitoral. (2016). Repositório de dados eleitorais: Arquivos dos candidatos das eleições de 2016. Brasília. 2016. Recuperado em 1 maio, 2019, de http://www.tse.jus.br/eleicoes/estatisticas/repositorio-de-dados-eleitorais-1/repositorio-de-dados-eleitorais

Tristão, G. (2002, outubro). Transparência na administração pública. Anais do Congresso Internacional Del Clad sobre La Reforma Del Estado Y de La Administración Pública, Lisboa, Portugal, 7.

Vieira, J. B. (2012). Transparência pública e corrupção nos municípios brasileiros: o impacto do governo eletrônico. Revista Jus Navigandi, 17(3226). Recuperado em 26 abril, 2019, de http://jus.com.br/revista/texto/21635

Zuccolotto, R., \& Teixeira, M. A. C. (2014). As Causas da Transparência Fiscal: evidências nos Estados Brasileiros. Revista Contabilidade Financeira - USP, 25(66), 242-254. Recuperado em 4 dezembro, 2018, de http://www.scielo.br/pdf/rcf/v25n66/pt_1519-7077-rcf-25-66-0242.pdf

Zuccolotto, R., Teixeira, M. A. C., \& Riccio, E. L. (2015). Transparência: reposicionando o debate. Revista Contemporânea de Contabilidade - UFSC, 12(25), 137. https://doi.org/10.5007/2175-8069.2015v12n25p137 